\title{
Social preferences for distributive outcomes of climate policy
}

\section{Svenningsen, Lea Skræp}

Published in:

Climatic Change

Link to article, DOI:

10.1007/s10584-019-02546-y

Publication date:

2019

Document Version

Peer reviewed version

Link back to DTU Orbit

Citation (APA):

Svenningsen, L. S. (2019). Social preferences for distributive outcomes of climate policy. Climatic Change, 157(2), 319-336. https://doi.org/10.1007/s10584-019-02546-y

\section{General rights}

Copyright and moral rights for the publications made accessible in the public portal are retained by the authors and/or other copyright owners and it is a condition of accessing publications that users recognise and abide by the legal requirements associated with these rights.

- Users may download and print one copy of any publication from the public portal for the purpose of private study or research.

- You may not further distribute the material or use it for any profit-making activity or commercial gain

- You may freely distribute the URL identifying the publication in the public portal

If you believe that this document breaches copyright please contact us providing details, and we will remove access to the work immediately and investigate your claim 


\section{Social preferences for distributive outcomes of climate policy}

\section{Lea S. Svenningsen}

\section{Climatic Change}

An Interdisciplinary, International Journal Devoted to the Description, Causes and Implications of Climatic Change

\section{ISSN 0165-0009}

Volume 157

Number 2

Climatic Change (2019) 157:319-336

DOI 10.1007/s10584-019-02546-y

\section{Climatic Change}

An Interdisciplinary, International Journal Devoted to the Description, Causes and Implications of Climatic Change

Editors: MICHAEL OPPENHEIMER GARY YOHE

Volume 157 - No. 2 - November II 2019

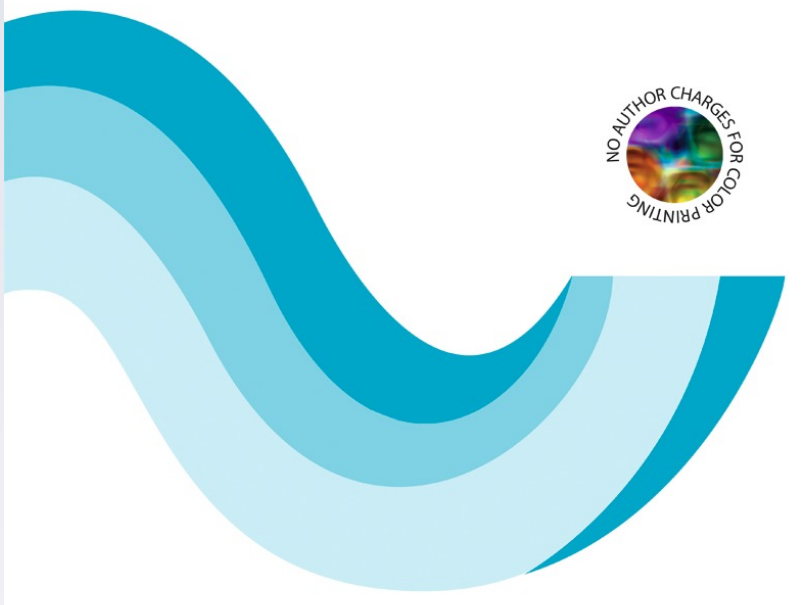

ISSN 0165-0009

刑 Springer

Springer 
Your article is protected by copyright and all rights are held exclusively by Springer Nature B.V.. This e-offprint is for personal use only and shall not be self-archived in electronic repositories. If you wish to self-archive your article, please use the accepted manuscript version for posting on your own website. You may further deposit the accepted manuscript version in any repository, provided it is only made publicly available $\mathbf{1 2}$ months after official publication or later and provided acknowledgement is given to the original source of publication and a link is inserted to the published article on Springer's website. The link must be accompanied by the following text: "The final publication is available at link.springer.com". 


\title{
Social preferences for distributive outcomes of climate policy
}

\section{Lea S. Svenningsen ${ }^{1}$}

Received: 7 January 2019 / Accepted: 27 August 2019/Published online: 7 September 2019

(C) Springer Nature B.V. 2019

\begin{abstract}
This study examines whether people exhibit social preferences for the distributive outcomes of climate policy when making actual donations towards such policies. In an online choice experiment, using a real donation mechanism, a sample of 95 members of the Danish public are provided $27 €$ and asked to make 16 donation choices among different climate policy options. The climate policies are described in terms of two main outcome variables: future effects on income in 2100 and present-time provision of co-benefits from climate policy. Both outcomes are described for three specific regions of the world, Western Europe, Southeast Asia and Sub-Saharan Africa. For each participant, one policy choice is drawn at random to be realized. The total amount donated by participants is used to purchase and withdraw $\mathrm{CO}_{2}$ quotas and credits in the European Emission Trading Scheme and as donations to the UN Adaptation Fund. The results indicate that distributional outcomes matter for people when they donate to climate policy and that elements of both inequity aversion and general altruism influence the choice of climate policy. The findings contribute towards an empirical foundation for the use of equity weights in determining the social cost of carbon, with the implication that the price on greenhouse gas emissions should be higher due to the concern for distributional impacts.
\end{abstract}

\section{Introduction}

Climate change is projected to generate physical impacts that are unequally distributed globally, with poorer regions being subjected to more adverse impacts than richer regions (IPCC 2014). This will give rise to uneven consequences for the general wealth of future generations and indicates that climate policies intended to mitigate the impacts of climate

Electronic supplementary material The online version of this article (https://doi.org/10.1007/s10584-01902546-y) contains supplementary material, which is available to authorized users.

Lea S. Svenningsen

leasks@dtu.dk

1 Climate Risks and Economics, Sustainability Division, Department of Management Engineering,

Technical University of Denmark, Kongens Lyngby, Denmark 
change therefore also implicitly influence the distribution of wealth for future generations (Klinsky and Dowlatabadi 2009). Policymakers arguably need to consider the current populations' preferences for the implicit distributional wealth effect, herein also deciding how to deal with such social preferences when designing climate change policies. One approach is to include social preferences the social cost of carbon (SCC) through the introduction of equity weights (Anthoff and Tol 2010; Pearce 2003; Tol 2011). Anthoff and Tol (2010) demonstrate that the consequences of introducing social preferences for the distributive outcomes of climate change results in a higher (albeit heterogeneous) cost of not mitigating climate change, hereby establishing the policy relevance of considering social preferences in climate policy design. However, an empirical investigation of how people value distributional impacts from climate change policies has yet to be undertaken. The contribution of this paper is to address this question by conducting an online choice experiment with a real donation mechanism. It provides an empirical foundation for the role and influence of social preferences for the distributive outcomes of climate policy.

Within the discipline of behavioural and experimental economics, the term social preferences has been used to describe how some people in different economic contexts prefer outcomes that benefit others in addition to themselves (Andreoni 1990; Andreoni et al. 2010; Bardsley and Sugden 2006; Fehr and Schmidt 1999a, 2006; Fischbacher and Gächter 2010). Several papers have examined the relevance of social preferences in the context of climate policy, in survey and empirical or theoretical papers. Survey papers have focused on the role of behavioural economics in general (Brekke and Johansson-Stenman 2008), how social norms influence preferences for climate policy (Alló and Loureiro 2014) or the concepts of climate justice used in the formulation and negotiation of climate policy (Pottier et al. 2017). Kverndokk (2018) combines a literature survey with theoretical models to study preferences for distributional outcomes in a North-South modelling framework. The empirical papers have typically focused on two different target populations, climate negotiators and private households, when examining the role of social preferences. Papers have examined how international climate change negotiators judge different justice principles (Lange et al. 2007, 2010), and measured their level of inequality aversion (Dannenberg et al. 2010). Private households have been surveyed on their preferences for the cost distribution of $\mathrm{CO}_{2}$ mitigation (Cai et al. 2010; Carlsson et al. 2012; Gampfer 2014) and their understanding of justice principles in relation to burden-sharing (Schleich et al. 2016), as well as studying people's self-interested use of equity principles (Brick and Visser 2015; Groh and Ziegler 2018). Finally, the theoretical papers have explored the use of equity weights (Anthoff et al. 2009; Anthoff and Tol 2010) and the tradeoff between intra- and intergenerational equity (Kverndokk et al. 2014).

A relevant question to consider is which characterization of social preferences best describes preferences for distributive outcomes of climate policy, given that different forms of social preferences are likely to be applicable to describe behaviour in any given context (Cappelen et al. 2007; Clément et al. 2015). In this paper, we develop and describe two different classifications of social preferences for the distributional impacts of climate policy that we term Inequity Averse Altruists and Altruists. Both classifications are directly inspired both by recognized justice principles relevant for distributive outcomes (Faravelli 2007; Konow 2001, 2003) and by classic models of social preferences in the behavioural economics literature (Andreoni 1990; Fehr and Schmidt 1999b). The classification as Inequity Averse Altruists describes the social preferences of people who prefer climate policies that reduce the impacts of climate change more for the poorest individuals, relative to policies reducing impacts for more affluent people. The Altruist classification captures social preferences that 
are not concerned with whom the impacts of climate change affect, but rather concerned about supporting climate policies that minimize the aggregate impact on income across all individuals. The classification as Inequity Averse Altruist can be directly linked to the needs principle, whereas the Altruist classification is linked to the efficiency principle (Konow 2001), entailing two different allocations of resources, e.g. distributive outcomes of climate policy. In the context of our study, adhering to the efficiency principle dictates a minimization of the aggregate income loss, which is achieved by preferring policies that benefit the rich regions as the policy here, by design, generates the largest economic loss. ${ }^{1}$ Whereas adhering to the needs principle implies preferring policies that favours the poorer regions. However, the two referred justice principles, need and efficiency, are not the only likely justice principles or motivations that could drive the observed social preferences for distributive outcomes. As an example, the Inequity Averse Altruist could be motivated by principles such as the polluterpays or the ability-to-pay (Pottier et al. 2017), and Altruists could be motivated by a rational approach to efficiency that does not involve elements of altruism or perhaps even self-interest regarding the region that the participant inhabits. The reference to known justice principles in the literature is typically featured in the discussion of who should pay for mitigation and adaptation action now, and are thus not directly related to future distributional impacts of climate change. This does not exclude the application of these principles to the research questions posed in this paper, but it makes the interpretation less straightforward, which is the primary motivation for why this paper argued that the need and efficiency principles should be seen as the primary justice arguments behind the two proposed social preference characterizations, Inequity Averse Altruists and Altruists.

The method used in this paper to identify social preferences for distributive outcomes of climate policies is an Internet-based, discrete choice experiment (DCE) using a real donation mechanism to incentivize the decision context. Applying the DCE method introduces the possibility of hypothetical bias, which refers to the finding that when people are asked to state their hypothetical willingness to pay for a given good, they tend to overstate their willingness to pay, compared to a situation where they actually pay for the good (List and Gallet 2001; Murphy et al. 2005). Several papers have found that introducing real economic incentives to valuation methods does reduce the hypothetical bias (Johansson-Stenman and Svedsäter 2012; Ready et al. 2010; Taylor et al. 2010), while some studies have found little or no effect (Cameron et al. 2002; Carson et al. 1996; List et al. 2006). As hypothetical bias has been found to be more pronounced for public goods (Murphy et al. 2005), and especially for public goods with a high moral content (Johansson-Stenman and Svedsäter 2012), such as the good studied in this paper, real monetary incentives were used in this study in an attempt to alleviate this concern. This study introduced a real donation mechanism that endowed participants with money, then asking them to donate them towards climate mitigation and adaptation, implemented through purchasing and subsequent cancelling of $\mathrm{CO}_{2}$ quotas and credits from the European Emission Trading Scheme (EU ETS) and as donations to the UN Adaptation Fund. Previous studies have applied similar real donation mechanisms, such as the studies by Löschel et al. (2013), Diederich and Goeschl (2014), and Uehleke and Sturm (2017), where participants are given the option between cash and a European Union Allowance (EUA) that would be deleted after the completion of the experiment.

Although the experiment in this paper partly uses the same mechanism to incentivize the decision of the participants (deletion of EUA's), the focus here is on the outcome from the

\footnotetext{
${ }^{1}$ This is an artefact of the results from the Fund integrated assessment model and our subsequent choices regarding the design of the attribute levels.
} 
mitigation and adaptation mechanism, specifically the distributional effects of climate change impacts. This implies a trade-off between the benefits of an incentivized economic experiment in terms of external validity of the presented hypotheses tests and on the other hand the perceived consequentiality of the participants' donation towards climate policies. As it was not possible to secure a donation mechanism that exclusively worked towards mitigating distributional impacts of climate change in the three regions, we selected mechanisms that could be reasonably associated with the presented climate policies and their distributional outcomes. This caveat and its implications for the results presented are discussed in more detail in the concluding discussion.

Using a sample of the Danish population, 95 participants were endowed with 200 DKK $(\sim 27 €)$ before participating in a discrete choice experiment, involving 16 donation choices related to climate policy. Each climate policy was described in terms of two outcome variables: (1) future income effects in the year 2100 as a result of climate policy and (2) present-day provision of co-benefits from mitigation actions. Both effects were described for three specific regions of the world, Western Europe, Southeast Asia and Sub-Saharan Africa. For each participant, one of the 16 donation choices was selected at random to be realized. The participant's earnings were the difference between the amount donated to the selected climate policy and the original endowment. Analysing the donation choices, this paper finds evidence of social preferences for distributive outcomes of climate policy when people make actual donations towards climate policies, suggesting that elements of inequity aversion and general altruism influence the choice of climate policy.

\section{Materials and method}

\subsection{Study context}

The study considers effects of climate policy in three different regions of the world: Western Europe (WE), Southeast Asia (SEA) and Sub-Saharan Africa (SSA), which are regions commonly used in integrated assessment models such as the FUND model (Anthoff and Tol 2010). Figure 1 displays the regions in the study.

The study focuses on two effects of climate policy in these three regions. The first effect is the impact that a specific climate policy would have on future average income in 2100 , by lowering the expected level of climate change and thus the expected economic loss to society. The year 2100 was chosen as reference year in accordance with the approach in much of the scientific literature on climate change (IPCC 2014). Participants were given the scenario that without additional investment in climate policy, people living in the three regions in the year 2100 would suffer a loss of $5 \%$ in yearly, average income due to climate change. The effect of additional climate policy initiatives (a mixture of mitigation and adaptation policies) would reduce this loss and create a gain in income, in comparison with no additional climate policy action (the status quo). This effect is called the "income effect" attribute, and the levels of this attribute were defined in accordance with expected levels of climate change impact from integrated assessment models at the time. ${ }^{2}$ Please refer to Table 1 for attributes and levels.

The second effect of climate policy considered was the provision of present-day co-benefits in the form of "fewer cases of respiratory diseases" in any of the three regions, called the "co-

\footnotetext{
${ }^{2}$ The $5 \%$ status quo loss and the levels of the income effect attribute were set using the online appendix to Anthoff and Tol (2010). Please refer to the Electronic Supplemental Material for more information regarding the survey and attribute design.
} 


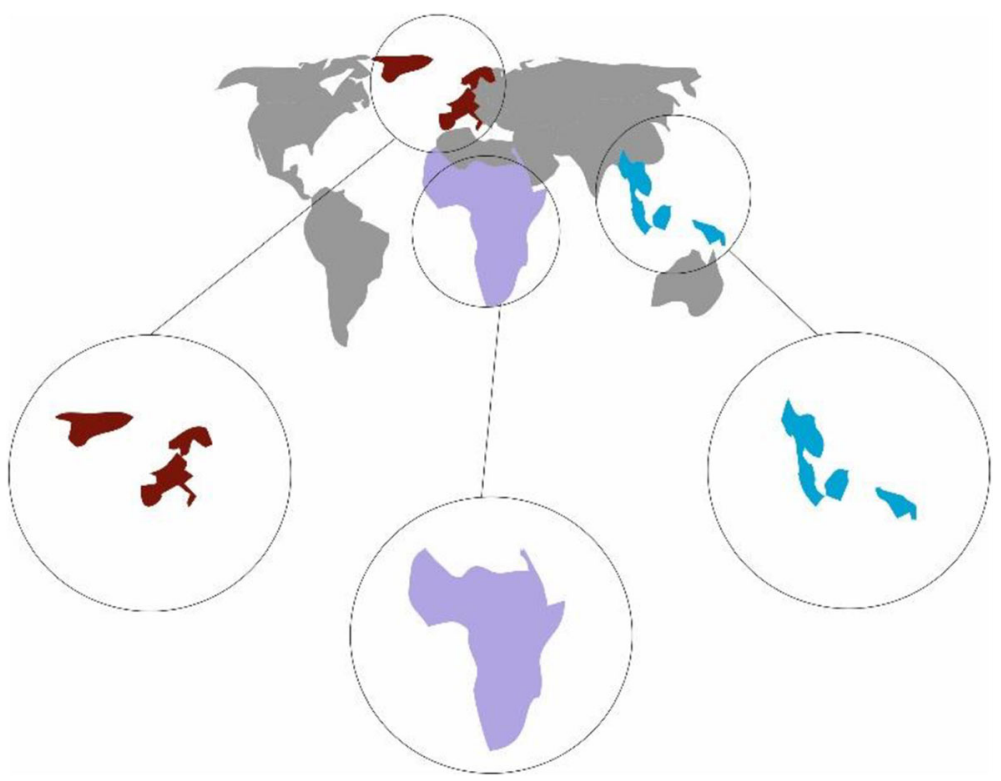

Fig. 1 Regions included in the study: (WE) marked with purple, (SEA) marked with blue and (SSA) marked with lilac

benefit" attribute. Participants were informed that the mitigation component of climate policy would reduce $\mathrm{CO}_{2}$ emissions through efforts targeted at lowering fuel consumption and changing combustion technologies in sectors such as industry, transportation and households, ${ }^{3}$ which would also result in lower levels of air pollution.

The survey explained to participants that the presented climate policies included either mitigation and adaption efforts or only adaptation effort and participants were informed that this could be inferred from the co-benefit attribute on the choice card. If it was specified as "no effect", this implied that the considered policy only included adaptation efforts.

\subsection{The real donation mechanism}

A central aspect of the study is the economic incentive provided to participants, using a real donation mechanism. An online survey panel recruited the participants, inviting them via email to participate in the survey. The email specified that if they participated in this survey, they would be able to earn up to 18,000 points or the equivalent of $200 \mathrm{DKK} / 27 €$, depending on their choices throughout the survey. ${ }^{4}$ In an earlier, similar study, the average response time was 20 min, suggesting that the hourly wage of participation in this experiment was $600 \mathrm{DKK} \sim 80$ $€$, which places the payment at the high end of comparable studies. ${ }^{5}$ By simply giving participants the endowment, there is a risk of "windfall or house money" effects influencing

\footnotetext{
${ }^{3}$ Unfortunately, there was no feasible way of identifying this specific feature of the presented climate policy, as $\mathrm{CO}_{2}$ quotas and credits were bought and erased without the possibility of specifying the origin of reduction.

${ }^{4}$ The individuals participating in the Internet panel earn points when they answer a survey for the company. These points can be exchanged for gift certificates to a wide variety of non-food and food stores, as well as used to enter lotteries and as donations to good causes.

${ }^{5}$ In Löschel et al. (2013) participants were endowed with $40 €$, and the experiment lasted 60-75 min.
} 
Table 1 Attributes and levels

\begin{tabular}{|c|c|c|c|c|c|c|}
\hline Attributes & \multicolumn{5}{|l|}{ Levels } & Status quo \\
\hline \multirow{4}{*}{ Co-benefit from regional mitigation efforts } & \multirow{4}{*}{\multicolumn{5}{|c|}{$\begin{array}{l}\text { Fewer cases of respiratory diseases (Western Europe) } \\
\text { Fewer cases of respiratory diseases (Southeast Asia) } \\
\text { Fewer cases of respiratory diseases (Sub-Saharan } \\
\quad \text { Africa) } \\
\text { No effect }\end{array}$}} & \multirow{4}{*}{ No effect } \\
\hline & & & & & & \\
\hline & & & & & & \\
\hline & & & & & & \\
\hline \multicolumn{7}{|c|}{ Income effect in terms of per capita income loss, DKK } \\
\hline Western Europe & \multicolumn{2}{|l|}{42,000} & 16,800 & \multicolumn{2}{|c|}{8400} & 42,000 \\
\hline Southeast Asia & 21,000 & 16,800 & 8400 & \multicolumn{2}{|c|}{4200} & 21,000 \\
\hline Sub-Saharan Africa & \multicolumn{2}{|l|}{10,500} & 4200 & \multicolumn{2}{|c|}{2.100} & 10,500 \\
\hline Donation, DKK & 10 & $20 \quad 40$ & 6090 & 120 & 200 & 0 \\
\hline
\end{tabular}

the elicited preferences (Cherry, Frykblom et al. 2002, Clark 2002, Glenn 2007). We could have included a real-effort task before participants commenced the survey, but this was judged as adding too much unwanted complexity to the survey. Instead, we chose to generate a sense of entitlement by telling respondents both in the invitation email and at the beginning of the survey that they would receive remuneration for their participation, as the survey would be more demanding than the normal surveys distributed to the panel. This method resembles that used in Löschel, Sturm et al. (2017) where participants were told that they would receive remuneration for their time spent in the experiment.

The actual donations to climate policy were fixed in the interval 0-200 DKK (see Table 1 for levels). Each participant made 16 donation choices, of which one donation was selected at random to be realized. Participants were informed that they could choose how much of the endowment to keep or donate to climate policy and that all the realized donations would be used to reduce $\mathrm{CO}_{2}$ through purchase and deletion of $\mathrm{CO}_{2}$ quotas and credits in the EU ETS, and/or donated to the UN Adaptation Fund. ${ }^{6}$ Participants were given the opportunity to click on links that would direct them to the official websites with information on the EU ETS and the UN Adaptation Fund. We informed participants that the researchers behind the study would be responsible for purchasing quotas and credits and for donations to the UN Adaptation Fund and that the distribution of funds between mitigation and adaption effort was decided by the choices made by them and the other participants. In order to keep a focus on the distributional issues and to reduce the cognitive load on the participants, we chose to abstain from a detailed explanation of the mechanism for distributing funds between mitigation and adaptation effort. ${ }^{7}$ If participants chose to donate, they had the option to receive documentation for the total amount used to purchase $\mathrm{CO}_{2}$ quotas/credits and donated to the UN Adaptation Fund, provided they supplied their email address. This was done to increase the credibility of the transactions taking place. ${ }^{8}$

\footnotetext{
$\overline{{ }^{6} \text { Because we purchased both } \mathrm{CO}_{2}}$ quotas and credits, we could ensure that $\mathrm{CO}_{2}$ reduction was possible both in the EU and elsewhere globally, making the co-benefit in regions other than WE realistic.

${ }^{7}$ If the randomly drawn donation decision included a policy alternative with provision of co-benefits in any of the three regions, then the donated amount was split 50/50 to mitigation (EU ETS) and adaptation effort (UN adaptation fund). If the chosen alternative did not include the provision of co-benefits, the entire donated amount was allocated to adaptation effort (UN adaptation fund). As rightly pointed out by a reviewer, it would have made it easier for participants to fully understand the impact of their donation, if the donation only included one option. However, given that our research question and design specified two distinct attributes that were linked to mitigation (co-benefit) and adaptation (income effects), we needed two donation options, in order to allow variation in one attribute independent of the level of the other attribute.

${ }^{8}$ Eighteen out of 95 participants supplied their email address.
} 
Participants were informed that the difference between the donated amount and the original endowment of 200 DKK would be paid out in points to the participants when the survey closed and no later than the 18th of March 2016. In the survey, after making their choices, participants were informed about which donation decision that was realized and the number of points that would be transferred to their user account with the survey panel.

\subsection{Survey strategy and data construction}

The survey was administered through Userneeds, a company specializing in online surveys with an online panel of more than 95,000 members of the general population in Denmark. The company has reliably handled several data collections involving scientific choice experiments and guarantees its participants complete anonymity. The survey ran in February 2016, and 1008 were invited to participate, of which 101 completed the survey. ${ }^{9}$ The survey was closed once a minimum population of representative participants had completed the survey; thus, a standard response rate cannot be estimated. Of the 101 participants, 10 always chose not to donate, and of these 10, 6 were characterized as protesters ${ }^{10}$ and excluded from the sample, leaving a sample of 95 respondents making 1520 choice observations. The average response time was $23 \mathrm{~min}$, with a standard deviation of $8 \mathrm{~min}$. The sample was designed to be representative in terms of age, gender and income, and descriptive statistics indicate that the sample was representative of gender and income, whereas the sample on average is older than the population of Denmark. For some of the educational characteristics, the sample matches the general population, suggesting that the sample contained the same proportion of people with secondary and tertiary education as the public. The sample is overrepresented with respect to participants holding a vocational education and underrepresented with respect to participants with a primary education. ${ }^{11}$

\subsection{Econometric models}

The prevalence and stability of social preferences for distributive outcomes of climate policy is investigated in a random parameters logit (RPL) model, which is based on the random utility framework (McFadden 1973), combined with Lancaster's theory on the characteristics of demand (Lancaster 1966). This suggests that we can model participant $n$ 's utility $(U)$ for choice $i$ as:

$$
U_{\mathrm{ni}}=\beta x_{\mathrm{ni}}+\varepsilon_{\mathrm{ni}}
$$

where $\beta$ is a vector of parameter coefficients to be estimated, $x_{\mathrm{ni}}$ are the observed parameters, such as individual characteristics and the choice attribute levels, and $\varepsilon_{\mathrm{ni}}$ is the unobserved, individual stochastic error term, assumed to be type I extreme value distributed.

\footnotetext{
${ }^{9}$ The allocated research budget limited the number of participants we could invite to participate in the study. In total, 221 persons participated in the survey, but 120 of these participants had participated in an earlier, different version of the survey and are therefore excluded from the analysis in this paper. The choice to resample a group of respondents was taken in order to investigate both the possible influence of being resampled and the potential influence of an economic incentive upon the social preferences of distributive outcomes. Readers interested in this comparison are referred to (Svenningsen and Jacobsen 2018)

${ }^{10}$ Participants were classified as protesters if they lacked faith in the presented scenarios, e.g. agreed to a statement of climate change being a global problem, which meant that Denmark should not be the only country engaging in additional climate policy, or they agreed to a statement of not wanting to pay for a policy that did not indicate how many tonnes $\mathrm{CO}_{2}$ would be reduced.

${ }^{11}$ A table with descriptive statistics can be found in the online Electronic Supplemental Material.
} 
The RPL model allows for a heterogeneous distribution of preferences within the sample instead of assuming that all individuals have the same sensitivity to the estimated parameters (Train 2009). The choice probability of the RPL model is:

$$
P_{n i}=\int \prod_{t=1}^{T} \frac{e^{\beta_{n} x_{n i t}}}{\sum_{j} e^{\beta_{n} x_{n j t}}} f(\beta) d \beta
$$

Equation (2) captures that the estimated coefficient $\beta$ varies over participants, with a density described by $f(\beta)$. In RPL models, the distributional assumptions of the random parameters are made by the researcher (Hensher and Greene 2003), and here, a normal distribution is assumed for all random parameters, thereby allowing for both negative and positive preferences for each attribute. ${ }^{12}$ As we have specified both price and non-price coefficients to be normally distributed, an investigation of welfare measures would have to correct for the theoretically unidentified distribution of the ratio of two normally distributed coefficients (Daly et al. 2012). This could be mediated by using the median of the willingness to pay (WTP) distribution as a benchmark for WTP comparisons, as suggested by Bliemer and Rose (2013). However, this paper does not pursue the interpretation of welfare measures for climate policy, and therefore, this aspect is not further dealt with.

The estimated RPL model allows for correlation between the estimated random parameters, which is often a more realistic assumption than not allowing for correlation between the random parameters (Hensher and Greene 2003; Revelt and Train 1998). In the specific context given in this paper, it seems reasonable to assume that preferences for either mitigation or adaptation efforts across the three regions could be linked, e.g. that a participant's preference for co-benefits in WE is related to the preference for co-benefits in the other two regions. Furthermore, the specification of the two social preference types, Inequity Averse Altruists and Altruists, implicitly assumes a relationship between one parameter across the three regions, and as such, it makes sense to explore the implications of this assumption further.

The estimated utility function is:

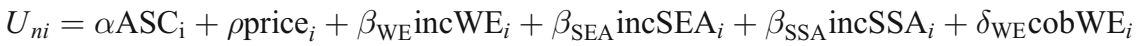

$$
\begin{aligned}
& +\delta_{\mathrm{SEA}} \operatorname{cobSEA}_{i}+\delta_{\mathrm{SSA}_{\mathrm{A}}} \operatorname{cobSSA}_{i}+\varepsilon_{n i}
\end{aligned}
$$

The parameter coefficient $\beta$ 's capture the utility effect of income effects (inc) in all three regions, while the $\delta$ 's capture the utility effect of co-benefit (cob) in all three regions. $\alpha$ is the coefficient for the alternative specific constant, the coefficient for the cost of the donation is captured by $p_{j}$, and $\varepsilon_{i j}$ represents the random error term. The parameter coefficients for the regional income effects and for the cost of donation are

\footnotetext{
${ }^{12}$ A previous, related study indicated that a non-trivial share of the sample had a positive price coefficient, suggesting that they were willing to sacrifice money in order to support climate policy (Svenningsen and Thorsen 2017). To allow for such preferences in the present study, the price parameter was assumed normally distributed. Several distributional forms were tested for the price parameter, including a lognormal distribution, triangular distribution and discrete, 2 class distribution, but in terms of stability, the assumption of a normally distributed price outperformed all other specifications. The instability of the price parameter in the other model specifications did not influence the interpretation of the other utility parameters, nor the relationship between them. Only in the case where no preference heterogeneity was allowed (fixed parameter on price) did the relationship between the co-benefits in all three regions change, but the conclusions with respect to the relationship between the income effects remained stable. The models assuming a fixed price had the lowest performance in terms of model fit. All sensitivity tests are available upon request.
} 
expected to be negative, assuming that people to react negatively to larger economic losses and increases in the cost of the donation. The coefficients on the regional cobenefits are expected to be positive, assuming that people gain utility from providing fewer cases of respiratory diseases in the three regions.

\subsection{Social preference hypotheses}

The classification tests of social preferences for the distributive outcomes of climate policy are conducted through Wald tests on the estimated coefficients for the income effect and co-benefit parameters in Eq. (3).

The Inequity Averse Altruist classification is based on the premise of assigning greater value to income effects and co-benefits in the two poorer regions of the study, e.g. SEA and SSA, compared to WE. This implies the evaluation of the following inequities:

Inequity Averse Altruists : $\left|\beta_{\mathrm{WE}}\right|<\left|\beta_{\mathrm{SEA}}\right|<\left|\beta_{\mathrm{SSA}}\right|$ and $\left|\delta_{\mathrm{WE}}\right|<\left|\delta_{\mathrm{SEA}}\right|<\left|\delta_{\mathrm{SSA}}\right|$

The conditions imply that for a one-unit increase in the income effect or co-benefit attribute in each region, Inequity Averse Altruists' marginal utility is statistically significantly more impacted by income losses and co-benefits in a poorer region compared to a richer region.

The Altruist classification is characterized by showing no sensitivity towards who receives the income effect or co-benefits, rather this classification captures an overall concern for the outcome of climate policy across regions. This implies the evaluation of the following inequities:

$$
\text { Altruists : }\left|\beta_{\mathrm{WE}}\right|=\left|\beta_{\mathrm{SEA}}\right|=\left|\beta_{\mathrm{SSA}}\right| \text { and }\left|\delta_{\mathrm{WE}}\right|=\left|\delta_{\mathrm{SEA}}\right|=\left|\delta_{\mathrm{SSA}}\right|
$$

The conditions imply that for a one-unit increase in the income effect or co-benefit attribute in either region, the marginal utility of the Altruist is not statistically significantly different across the three regions.

Two things should be noted here. First, while the focus in this paper is on the two classifications of social preferences, it is likely that other preference characterizations are relevant to the study context. Particularly, one would expect the presence of a group of participants displaying non-altruistic preferences. Secondly, because our Danish respondents live in WE, they may associate changes in the two attributes with direct utility benefits for themselves, thus potentially introducing a self-interest bias. As an example, they might associate co-benefits with direct utility benefits for themselves and their families and derive bequest values from enhancing future incomes of their children's children in their own region. If they are young enough, they may even worry about the impact on their own lifetime income. This may result in the inequity aversion not being strong enough to dominate in the inequalities involving WE, even if present. Thus, a reduced, sufficient test for the Inequity Averse Altruist and Altruist types, in this case, is a test of these inequalities only:

$$
\begin{gathered}
\left|\beta_{\mathrm{SEA}}\right|<\left|\beta_{\mathrm{SSA}}\right| \text { and }\left|\delta_{\mathrm{SEA}}\right|<\left|\delta_{\mathrm{SSA}}\right| \\
\left|\beta_{\mathrm{SEA}}\right|=\left|\beta_{\mathrm{SSA}}\right| \text { and }\left|\delta_{\mathrm{SEA}}\right|=\left|\delta_{\mathrm{SSA}}\right|
\end{gathered}
$$

It should be noted that inequity aversion may still be strong enough for one or more of the inequalities in Eqs. (4) and (5) involving WE to hold, but this is an empirical question. All of the presented inequalities are tested explicitly in the following section. 


\section{Results}

\subsection{The donation pattern}

Before turning to the results of the econometric models, this subsection describes the donation choices of the participants. Figure 2 shows the distribution of choices for each of the three policy alternatives. From this, it is visible that the status quo policy option is chosen somewhat less frequent compared to the other two alternatives, indicating that a substantial share of the choices was made towards climate policies and that our participants often picked choices that would diminish their economic payoff. Figure 2 also displays the percentage of all donation choices for each donation level, indicating that a little less than half of the donations $(40 \%)$ were donations of 0 DKK, which suggests that participants were sensitive to the price of the chosen policy alternative. Focusing only on the choices of the two climate policy alternatives, policy 1 and 2, the data indicate that the share of respondents choosing either of these two policies drops when the price of the policy increases, but also that at the high donation levels, approximately $30 \%$ of all choices is a donation. The average amount donated to climate policy was 54 DKK (approx. $7.25 €$ ), with a standard deviation of $61 \mathrm{DKK}$, and represents $27 \%$ of the endowment of $200 \mathrm{DKK} .{ }^{13}$ The average amount donated in this study is comparable to the typical average donation level found in voluntary contribution mechanism (VCM) experiments, as summarized in John (1995), which suggests that people on average donate 20-30\% of their endowment. This suggests that our participants "bought" into the experimental context and reacted to the experiment in a similar manner as typically seen in the experimental economics literature.

\subsection{Econometric analysis}

Table 2 presents the result of the RPL model with full correlation between the random parameters. The model is estimated in STATA 13.1, using the mixlogit command (Arne 2007) with simulation of the log-likelihood function, using 1000 Halton draws per participant and random parameter.

The parameter estimates for income effects in all three regions are negative and significant, indicating that participants on average disliked future income losses in all three regions. Wald tests indicate that income losses in SEA and SSA generate significantly more disutility than income losses in WE, with the difference being statistically significant between WE-SEA and WE-SSA (see Table 3). These results suggest participants in the sample, on average, experienced more disutility from income losses in the poorer regions, and the classification of preferences as Inequity Averse Altruists cannot be rejected for the difference between WE-SEA and WE-SSA. In Section 2.5, we theoretically discussed the possibility of a self-interest bias in the estimated parameter coefficients for WE. This could be partially inferred from the size of the parameter estimate for income effects in WE, but here, the model results indicate that the coefficient for WE is lower than that of SEA and SSA, suggesting

\footnotetext{
${ }^{13}$ The average donated amount is based only on choices of climate policy, e.g. alternative 1 and 2 . If the status quo option choices are included, the average drops to $41 \mathrm{DKK}$.
} 

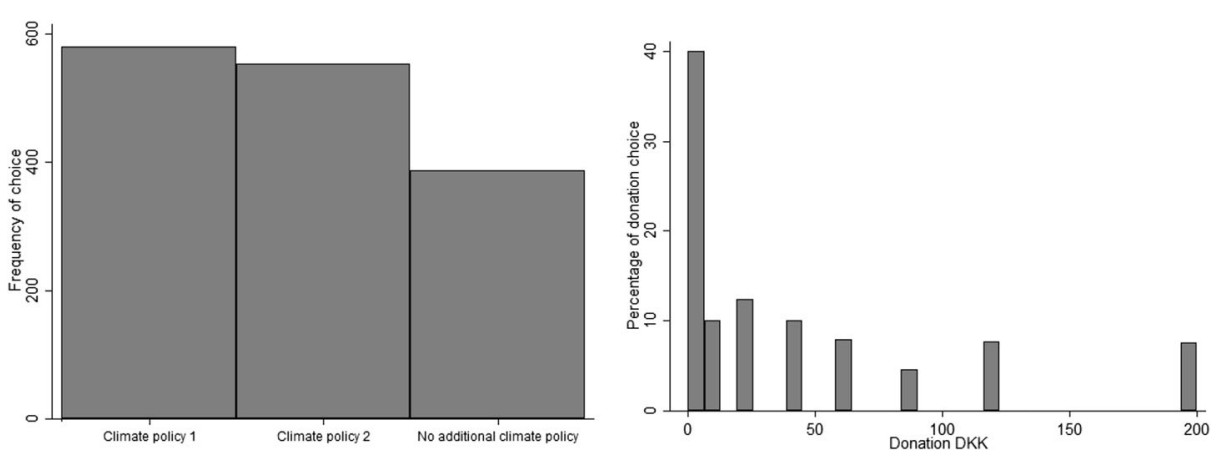

Fig. 2 Histogram showing the frequency of choice of each of the three climate policies and bar chart showing the distribution of money (DKK) donated to climate policy. In total, there are 1520 observations, distributed across 95 participants, each making 16 choices

perhaps that inequity aversion was strong enough to dominate the self-interest bias. If the reduced tests presented in Eqs. (6) and (7) are used to test the social preference hypotheses, we would not be able to reject the equality of coefficients for income effects in SEA and SSA, meaning we would not be able to reject the Altruist classification.

The parameter estimates for the co-benefits in all three regions are positive and significant, indicating that participants gained utility from providing fewer cases of respiratory diseases. Wald tests in Table 3 indicate no significant locational preference regarding where the cobenefits are provided; thus, we are unable to reject the classification of Altruist for this type of outcome.

Table 2 Estimation results, $n=$ 4560

\begin{tabular}{|c|c|c|c|c|}
\hline \multirow[t]{2}{*}{$\begin{array}{l}\text { Iable } 2 \text { Estimation results, } n= \\
4560\end{array}$} & & & \multicolumn{2}{|l|}{ Model 1} \\
\hline & & & Est. & $\mid z$ value $\mid$ \\
\hline & \multirow[t]{2}{*}{ ASC } & $\mu$ & -1.034 & 2.440 \\
\hline & & $\sigma$ & 2.228 & 3.540 \\
\hline & \multirow[t]{2}{*}{ incWE } & $\mu$ & -0.044 & 5.410 \\
\hline & & $\sigma$ & 0.050 & 6.630 \\
\hline & \multirow[t]{2}{*}{ incSEA } & $\mu$ & -0.087 & 7.310 \\
\hline & & $\sigma$ & 0.057 & 3.990 \\
\hline & \multirow[t]{2}{*}{ incSSA } & $\mu$ & -0.108 & 3.420 \\
\hline & & $\sigma$ & 0.269 & 7.670 \\
\hline & \multirow[t]{2}{*}{ cobWE } & $\mu$ & 1.552 & 5.200 \\
\hline & & $\sigma$ & 1.267 & 4.590 \\
\hline & \multirow[t]{2}{*}{ cobSEA } & $\mu$ & 1.888 & 5.560 \\
\hline & & $\sigma$ & 1.674 & 6.340 \\
\hline & \multirow[t]{2}{*}{ cobSSA } & $\mu$ & 1.615 & 4.930 \\
\hline & & $\sigma$ & 1.762 & 6.370 \\
\hline & \multirow[t]{2}{*}{ price } & $\mu$ & -40.228 & 7.000 \\
\hline & & $\sigma$ & 72.682 & 7.910 \\
\hline The table reports both mean $(\mu)$ & & \multicolumn{2}{|l|}{-881.262} \\
\hline and standard deviation $(\sigma)$ of & \multicolumn{2}{|l|}{$K$} & \multicolumn{2}{|l|}{44} \\
\hline each random parameter & \multicolumn{2}{|l|}{$\rho^{2}$} & \multicolumn{2}{|l|}{0.416} \\
\hline
\end{tabular}

Model 1 
Table 3 Wald tests of equality of coefficients in Model 1

Statistical significance level,

$* p<0.05, * * p<0.01$,

$* * * p<0.001$

\begin{tabular}{lc}
\hline & Model 1 \\
\hline Income effects & \\
WE $=$ SEA & $10.62^{* * *}$ \\
WE $=$ SSA & $4.68^{* * *}$ \\
SEA = SSA & 0.48 \\
Co-benefits & \\
WE $=$ SEA & 1.95 \\
WE $=$ SSA & 0.12 \\
SEA $=$ SSA & 1.48 \\
\hline
\end{tabular}

Increases in the price of climate policy have a negative and significant impact on utility, as does not choosing a climate policy captured by the negative and statistically significant ASC. ${ }^{14}$ The results also suggest significant preference heterogeneity, at a 5\% level, for all estimated parameters. Several of the estimated parameters have standard deviations $(\sigma)$ that are larger than the mean estimate $(\mu)$. These include the status quo option (ASC), income effects in Western Europe (incWE) and Sub-Saharan Africa (incSSA), co-benefits in Sub-Saharan Africa (cobSSA) and the price of climate policy (price). ${ }^{15}$

\subsection{Sensitivity analysis}

This section presents the results of a sensitivity analysis, using a latent class model to analyse the choice of climate policy. A latent class model assumes preference homogeneity within each class, but heterogeneity across classes (Greene and Hensher 2003). The number of modelled classes is three, both because BIC and AIC criteria indicated that this was the optimal number of classes and because this would facilitate the presence of both social preference types in each their separate class while allowing for a third "free" class.

The results in Table 4 indicate that a small majority, 52\% of the sample ( $\sim 50$ participants), belong to class 1 . This class reproduces almost the exact same preference pattern as in model 1 ; income effects in all three regions are negative and significant. Income effects in WE generate less disutility than income effects in SEA and SSA, and Wald tests confirm that this difference is statistically significant for all comparisons, including the comparison between SEA and SSA. This suggests that we cannot reject the classification of Inequity Averse Altruists for income effects in class 1. Furthermore, Wald tests indicate that we cannot reject the classification of Altruists for the provision of co-benefits, reconfirming the findings of model 1 . The cost coefficient is positive, but statistically insignificant, suggesting that respondents in this class had a low sensitivity to the price of the donation. Given the small sample size, this could be a result of poor identification combined with taste heterogeneity (Hess et al. 2013), but it could also be a possibility that respondents in this class simply ignored the cost of their donation. Class 2 contains approx. $30 \%$ of the sample ( $\sim 28$ participants), and the results indicate that this group of participants reacted negatively and statistically significant only to increases in the cost of the donation. This suggests that, for this group of participants, we only succeeded in measuring preferences for the donation mechanisms as such and not for the

\footnotetext{
${ }^{14}$ Coded as ASC $=1$ for each choice where the participant chose the status quo alternative.

15 The Electronic Supplemental Material contain a section that investigates and groups the estimated individual specific coefficients, in order to compare, on an individual level, the trade-offs between distributional preferences for the three regions.
} 
Table 4 Latent class model, three classes

\begin{tabular}{llll}
\hline & 1 & 2 & 3 \\
\hline Class share & 0.518 & 0.298 & 0.184 \\
ASC & $-3.548^{* * *}(1.052)$ & $19.08(332.6)$ & $-0.698(0.378)$ \\
incWE & $-0.031 * * *(0.004)$ & $-0.006(0.011)$ & $-0.003(0.008)$ \\
incSEA & $-0.058^{* * *(0.008)}$ & $-0.034(0.023)$ & $-0.029(0.015)$ \\
incSSA & $-0.111^{* * *}(0.017)$ & $0.068(0.041)$ & $0.019(0.031)$ \\
cobWE & $0.924 * *(0.161)$ & $18.99(332.6)$ & $1.464 * * *(0.326)$ \\
cobSEA & $0.862 * * *(0.153)$ & $19.99(332.6)$ & $0.735^{* *}(0.269)$ \\
cobSSA & $1.022^{* * *(0.156)}$ & $19.36(332.6)$ & $1.321 * * *(0.332)$ \\
price & $1.518(0.954)$ & $-129.0 * * *(18.00)$ & $-12.31 * * *(1.920)$ \\
$N$ & 4560 & & \\
$L L$ & -911.678 & & \\
\hline
\end{tabular}

Standard errors in parentheses

$* p<0.05, * * p<0.01, * * * p<0.001$

presented climate policy attributes. Class 3 contains $18 \%$ of the sample ( $\sim 17$ participants), which display positive and statistically significant preferences for the provision of co-benefits in all three regions while reacting negatively to increases in the price of a donation. Wald tests indicate that we cannot reject the classification of Altruists for the provision of co-benefits.

The identified preference heterogeneity for distributional outcomes of climate policy might be related to certain socio-demographic and attitude variables as previously found in the literature (Groh and Ziegler 2018). Several of these variables were tested in predicting the membership of the each of the three classes, such as participant age, gender, income, educational level, political affiliation, having donated to either environmental and humanitarian causes within the last year, perception of predicted impact of climate change and the current economic distribution of wealth. At a $10 \%$ significance level, only age and having donated towards environmental and humanitarian causes within the last year were found to be significant membership predictors. Compared to class 1, older people were less likely to be members of class 3 , and people who had donated towards environmental and humanitarian causes were less likely to be members of class 2 and 3 .

\section{Concluding discussion}

Understanding the public's preferences for the distributive outcomes of climate policy is vital for the design, efficiency and social welfare of such policies (Johansson-Stenman and Konow 2010), and thus a pertinent step in the efforts to meet the challenge of climate change. This paper investigates whether two theoretical characterizations of social preferences can be used to describe people's choice of climate policy. The policy implication is twofold. First, the existence of social preferences for distributional outcomes of climate policy can be used to inform the optimal level of carbon taxation, thus implicitly also the ambition level of national governments. Secondly, if people are concerned about the distributional impacts of climate change, then this information could be used to frame climate policies, in order to increase public support.

Using a sample of the Danish public, this paper finds evidence for the existence of social preferences for the distributive outcomes of climate policy. The results suggest that we cannot 
reject that the average person holds preferences in line with inequity aversion when it comes to future distributional impacts on income and that we cannot reject that the average preference for present-time distributional impacts in the form of co-benefits is general altruism.

However, the results also indicate the presence of significant preference heterogeneity for these distributional outcomes. The results of the sensitivity analysis indicated that a small majority of participants expressed social preferences in accordance with the findings from the main model, e.g. inequity aversion for future income effects and general altruism for the provision of co-benefits, but also that this class of respondents had a low sensitivity to the cost of the donation. The results also revealed a class of participants who apparently only expressed preferences for the two donation mechanisms, expressing no preferences for distributional outcomes from climate policy, and a class of participants who strictly preferred the present time distributional outcome, e.g. the provision of co-benefits. Overall, the results from the sensitivity analysis nuance the conclusions reached in the main model. The models represent different ways of characterizing preference heterogeneity, but in terms of model performance, the main model outperforms the latent class model. Given the low sample size, the latent class estimation is problematic in terms of preference determination based on a low number of participants in each class. This aspect could be a likely driver behind the weak identification of many of the parameter estimates across classes, including the insignificant cost coefficient in the largest class.

The results of this paper hint that the classification of social preferences is sensitive to the outcome considered, which confirms the previous finding in the literature that people use different moral principles to evaluate mitigation and adaption policies (Klinsky et al. 2012). For future income effects, our model indicates that participants preferred policies that favoured poorer regions, whereas we found no evidence of locational preferences for the immediate provision of co-benefits. For both types of outcomes, we could not identify a statistically significant self-interest regarding the participants' own region (WE). This is not to suggest that these motives are not relevant in general, but our results do not confirm their importance in the described climate policy context.

The differing characterization of social preferences for income effects and co-benefits may not only be caused by the difference in the timing of the outcomes but could also be attributed to the specification of income effects as quantitative and co-benefits as qualitative. Previous studies have typically specified co-benefits from climate policy as qualitative (as in the present study), with results not producing a clear interpretation of people's preferences regarding the location of co-benefits, often referred to as locational preferences. However, it may be argued that the monetized income effects are formulated in a metric that people encounter in their everyday life, with existing literature having shown that relative income comparisons matter for people (Johansson-Stenman et al. 2002; Yamada and Sato 2016), making the preferences for such an attribute especially susceptible for elements inequity aversion.

This paper does not find any locational preference with regard to the provision of cobenefits, which resembles the finding in Diederich and Goeschl (2017), who also found no clear location preference. Previous studies have found mixed evidence for the effect of locational preference on people's willingness to pay (WTP) for climate policy. Some studies suggesting that WTP increases with implementation in their own country/region (Buntaine and Prather 2018; Carlsson et al. 2012; Longo et al. 2012; Torres et al. 2015), while other studies find a reverse effect with a clear preference for implementation in other regions (Baranzini et al. 2018). The presented climate policy context had a strong focus on distributional issues, which could have caused respondents to consider the effect in the two other regions (SEA and 
SSA) more, as compared to a situation where they are asked about their general preference for implementation site as in Carlsson et al. (2012).

The finding of no statistically significant self-interest regarding outcomes in the participants' own region could be a by-product of the climate policy context and the donation payment mechanism being too abstract. The donation context was arguably complex and challenging for the respondents' cognitive skills, because they were asked to consider effects in both time and space, which could have led to the respondents using heuristics or decision rules to navigate a challenging task, as seen in other choice experiment contexts (Hensher 2006; Hensher and Greene 2010).

Furthermore, the experimental design involved a trade-off between the focus on distributional social preferences, a credible payment vehicle, and the policy implementation description. As it was not possible to identify a donation mechanism that exclusively worked towards mitigating the distributional effects of climate change, we settled on mechanisms that could be reasonably associated with the focus on distributional outcomes from climate policy. The experimental design required two different donation mechanisms, chosen to be the EU ETS and the UN Adaptation Fund, in order to generate the experimental variation needed to test the social preference hypotheses across the climate policy attributes.

One could argue that there exists a risk of participants not perceiving the link between the presented climate policy alternatives and the two policy implementation instruments as credible and consequential. Thus, they may instead only relate to the two donation mechanism and simply pick climate policy alternatives with donation amounts that more or less equal their willingness to donate towards exactly these two mechanisms, essentially ignoring all other attributes. This would suggest that participants should have ignored the income effect and cobenefit attributes, and we should only have observed significant (and negative) coefficients for the "No additional policy" alternative as well as for the price of climate policy. The results of the sensitivity analysis indicate that this, in fact, was an accurate description for some of our participants, thus indicating that the missing 1:1 between policy options and donation mechanisms is a central caveat of our study. Ideally, this discrepancy could be resolved in future studies on the empirical foundation for social preferences. However, the results of the sensitivity analysis also indicate that the remaining two classes of participants on average reacted to one or both of the distributional outcomes of climate policy and thus exhibited clear preferences for the presented climate policy alternatives.

A caveat with respect to design and external validity is the small and mono-national sample. A larger sample would definitely provide a firmer foundation for the conclusions reached in this paper. Furthermore, in 2016, Denmark was ranked as 31st in a global comparison of GPD per capita, ${ }^{16}$ and although a trade-off in the donation setting was observed (e.g. people did not simply give their endowment away), it is in the author's opinion likely that the average donated amount is higher than it would have been in other, less wealthy countries. As identified in some experimental economics papers comparing the behaviour of different nationalities, Danes tend to be very collaborative (Engelmann and Normann 2010; Herrmann et al. 2008). Possible future work would benefit from focusing on establishing the relevance of distributional preferences in relation to climate policy in other regions/countries of the world to achieve a global, diversified measure of distributional preferences in relation to climate policy.

To conclude, the study presented in this paper provides additional support and an empirical foundation for the practice of accounting for social preferences for distributional outcomes of

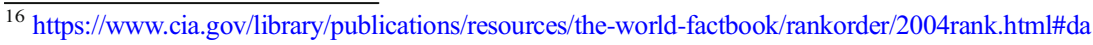


climate policy. The findings of this study indicate that such an effort is not only warranted by theoretical arguments but also justified through a description of people's preferences based on actual donations to climate policy. Policymakers seeking to increase the acceptability of proposed climate policy initiatives could benefit from stressing the distributional aspects of such policies.

Acknowledgements The author is very grateful to the three reviewers and the associate editor for helpful comments that improved the paper. The paper also benefitted from comments from participants at the EAERE 2017, Athens, and from discussion with Bo Jellesmark Thorsen.

\section{References}

Alló M, Loureiro ML (2014) The role of social norms on preferences towards climate change policies: a metaanalysis. Energy Policy 73:563-574

Andreoni J (1990) Impure altruism and donations to public Goods: A Theory of Warm-Glow Giving. The Economic Journal. https://doi.org/10.2307/2234133

Andreoni, J., Harbaugh, W. T., \& Vesterlund, L. (2010). Altruism in experiments. In Behavioural and Experimental Economics. doi https://doi.org/10.1057/9780230280786_2

Anthoff D, Tol RSJ (2010) On international equity weights and national decision making on climate change. J Environ Econ Manag 60(1):14-20

Anthoff D, Hepburn C, Tol RSJ (2009) Equity weighting and the marginal damage costs of climate change. Ecol Econ. https://doi.org/10.1016/j.ecolecon.2008.06.017

Arne Risa Hole, (2018) Fitting Mixed Logit Models by Using Maximum Simulated Likelihood. The Stata Journal: Promoting communications on statistics and Stata 7 (3):388-401

Baranzini A, Borzykowski N, Carattini S (2018) Carbon offsets out of the woods? Acceptability of domestic vs. international reforestation programmes in the lab. Journal of Forest Economics 32:1-12

Bardsley N, Sugden R (2006) Chapter 10 Human nature and sociality in economics. Handbook of the Economics of Giving, Altruism and Reciprocity. doi https://doi.org/10.1016/S1574-0714(06)01010-4

Bliemer MCJ, Rose JM (2013) Confidence intervals of willingness-to-pay for random coefficient logit models. Transp Res B Methodol 58:199-214

Brekke KA, Johansson-Stenman O (2008) The behavioural economics of climate change. Oxf Rev Econ Policy 24(2):280-297

Brick K, Visser M (2015) What is fair? An experimental guide to climate negotiations. Eur Econ Rev 74:79-95

Buntaine MT, Prather L (2018) Preferences for domestic action over international transfers in global climate policy. Journal of Experimental Political Science 5(2):73-87

Cai B, Cameron TA, Gerdes GR (2010) Distributional preferences and the incidence of costs and benefits in climate change policy. Environ Resour Econ. https://doi.org/10.1007/s10640-010-9348-7

Cameron TA, Poe GL, Ethier RG, Schulze WD (2002) Alternative non-market value-elicitation methods: are the underlying preferences the same? J Environ Econ Manag 44(3):391-425

Cappelen AW, Hole AD, Sørensen E, Tungodden B (2007) The pluralism of fairness ideals: an experimental approach. Am Econ Rev. https://doi.org/10.1257/aer.97.3.818

Carlsson F, Kataria M, Krupnick A, Lampi E, Löfgren Å, Qin P, .. Sterner T (2012) Paying for mitigation: a multiple country study. Land Econ 88(2):326-340

Carson RT, Flores NE, Martin KM, Wright JL (1996) Contingent valuation and revealed preference methodologies: comparing the estimates for quasi-public goods. Land Economics 80-99

Cherry, T. L., Frykblom, P., \& Shogren, J. F. (2002). Hardnose the dictator. American Economic Review, 92(4), 1218-1221

Clark, J. (2002). House money effects in public good experiments. Experimental Economics, 5(3), 223-231

Clément V, Rey-Valette H, Rulleau B (2015) Perceptions on equity and responsibility in coastal zone policies. Ecol Econ 119:284-291. https://doi.org/10.1016/J.ECOLECON.2015.09.005

Daly A, Hess S, Train K (2012) Assuring finite moments for willingness to pay in random coefficient models. Transportation 39(1):19-31

Dannenberg A, Sturm B, Vogt C (2010) Do equity preferences matter for climate negotiators? An experimental investigation. Environ Resour Econ 47(1):91-109

Diederich J, Goeschl T (2014) Willingness to pay for voluntary climate action and its determinants: fieldexperimental evidence. Environ Resour Econ 57(3):405-429 
Diederich J, Goeschl T (2017) Does mitigation begin at home? Discussion Paper Series, University of Heidelberg, Department of Economics

Engelmann D, Normann H-T (2010) Maximum effort in the minimum-effort game. Exp Econ 13(3):249-259

Faravelli M (2007) How context matters: a survey based experiment on distributive justice. J Public Econ 91(78):1399-1422. https://doi.org/10.1016/J.JPUBECO.2007.01.004

Fehr E, Schmidt KM (1999a) A theory of fairness, competition, and cooperation. Q J Econ. https://doi. org/10.1162/003355399556151

Fehr E, Schmidt KM (1999b) A theory of fairness, competition, and cooperation. Q J Econ 114(3):817-868

Fehr E, Schmidt KM (2006) Chapter 8 The economics of fairness, reciprocity and altruism - experimental evidence and new theories. Handbook of the Economics of Giving, Altruism and Reciprocity. doi https:/doi. org/10.1016/S1574-0714(06)01008-6

Fischbacher U, Gächter S (2010) Social preferences, beliefs, and the dynamics of free riding in public goods experiments. Am Econ Rev. https://doi.org/10.1257/aer.100.1.541

Gampfer R (2014) Do individuals care about fairness in burden sharing for climate change mitigation? Evidence from a lab experiment. Clim Chang 124(1-2):65-77

Glenn W. Harrison, (2007) House money effects in public good experiments: Comment. Experimental Economics 10 (4):429-437

Greene WH, Hensher DA (2003) A latent class model for discrete choice analysis: contrasts with mixed logit. Transp Res B Methodol 37(8):681-698

Groh ED, Ziegler A (2018) On self-interested preferences for burden sharing rules: an econometric analysis for the costs of energy policy measures. Energy Econ 74:417-426

Hensher DA (2006) How do respondents process stated choice experiments? Attribute consideration under varying information load. J Appl Econ 21(6):861-878

Hensher DA, Greene WH (2003) The mixed logit model: the state of practice. Transportation 30(2):133-176

Hensher DA, Greene WH (2010) Non-attendance and dual processing of common-metric attributes in choice analysis: a latent class specification. Empir Econ 39(2):413-426

Herrmann B, Thöni C, Gächter S (2008) Antisocial punishment across societies. Science 319(5868):1362-1367

Hess S, Shires J, Jopson A (2013) Accommodating underlying pro-environmental attitudes in a rail travel context: application of a latent variable latent class specification. Transp Res Part D: Transp Environ 25:4248

IPCC (2014) Contribution of Working Groups I, II and III to the Fifth Assessment Report of the Intergovernmental Panel on Climate Change. Switzerland, Geneva

John O. Ledyard, 1994. "Public Goods: A Survey of Experimental Research, University Library of Munich, Germany, revised 22 May 1994.

Johansson-Stenman O, Konow J (2010) Fair air: distributive justice and environmental economics. Environ Resour Econ. https://doi.org/10.1007/s10640-010-9356-7

Johansson-Stenman O, Svedsäter H (2012) Self-image and valuation of moral goods: stated versus actual willingness to pay. J Econ Behav Organ 84(3):879-891

Johansson-Stenman O, Carlsson F, Daruvala D (2002) Measuring future grandparents'preferences for equality and relative standing. Econ J 112(479):362-383

Klinsky S, Dowlatabadi H (2009) Conceptualizations of justice in climate policy. Clim Pol 9(1):88-108. https://doi.org/10.3763/cpol.2008.0583b

Klinsky S, Dowlatabadi H, McDaniels T (2012) Comparing public rationales for justice trade-offs in mitigation and adaptation climate policy dilemmas. Glob Environ Chang 22(4):862-876. https://doi.org/10.1016/J. GLOENVCHA.2012.05.008

Konow J (2001) Fair and square: the four sides of distributive justice. J Econ Behav Organ. https://doi. org/10.1016/S0167-2681(01)00194-9

Konow J (2003) Which is the fairest one of all? A positive analysis of justice theories. J Econ Lit 41(4):11881239

Kverndokk S (2018) Climate policies, distributional effects and transfers between rich and poor countries. Int Rev Environ Resour Econ 12(2-3):129-176

Kverndokk S, Nævdal E, Nøstbakken L (2014) The trade-off between intra-and intergenerational equity in climate policy. Eur Econ Rev 69:40-58

Lancaster KJ (1966) A new approach to consumer theory. J Polit Econ 74(2):132-157

Lange A, Vogt C, Ziegler A (2007) On the importance of equity in international climate policy: an empirical analysis. Energy Econ 29(3):545-562

Lange A, Löschel A, Vogt C, Ziegler A (2010) On the self-interested use of equity in international climate negotiations. Eur Econ Rev 54(3):359-375. https://doi.org/10.1016/J.EUROECOREV.2009.08.006 
Löschel, A., Sturm, B., \& Uehleke, R. (2017). Revealed preferences for voluntary climate change mitigation when the purely individual perspective is relaxed-evidence from a framed field experiment. Journal of Behavioral and Experimental Economics, 67, 149-160.

List JA, Gallet CA (2001) What experimental protocol influence disparities between actual and hypothetical stated values? Environ Resour Econ 20(3):241-254

List JA, Sinha P, Taylor MH (2006) Using choice experiments to value non-market goods and services: evidence from field experiments. Advances in Economic Analysis \& Policy 5(2)

Longo A, Hoyos D, Markandya A (2012) Willingness to pay for ancillary benefits of climate change mitigation. Environ Resour Econ 51(1):119-140

Löschel A, Sturm B, Vogt C (2013) The demand for climate protection-empirical evidence from Germany. Econ Lett 118(3):415-418

McFadden D (1973) Conditional logit analysis of qualitative choice behavior, Chapter 4 in Frontiers in Econometrics (P. Zarembka, ed.), Academic Press New York

Murphy JJ, Allen PG, Stevens TH, Weatherhead D (2005) A meta-analysis of hypothetical bias in stated preference valuation. Environ Resour Econ 30(3):313-325

Pearce D (2003) The social cost of carbon and its policy implications. Oxf Rev Econ Policy 19(3):362-384

Pottier A, Méjean A, Godard O, Hourcade J-C (2017) A survey of global climate justice: from negotiation stances to moral stakes and back. Int Rev Environ Resour Econ 11(1):1-53

Ready RC, Champ PA, Lawton JL (2010) Using respondent uncertainty to mitigate hypothetical bias in a stated choice experiment. Land Econ 86(2):363-381

Revelt D, Train K (1998) Mixed logit with repeated choices: households' choices of appliance efficiency level. Rev Econ Stat 80(4):647-657

Schleich J, Dütschke E, Schwirplies C, Ziegler A (2016) Citizens' perceptions of justice in international climate policy: an empirical analysis. Clim Pol 16(1):50-67

Svenningsen LS, Jacobsen JB (2018) Testing the effect of changes in elicitation format, payment vehicle and bid range on the hypothetical bias for moral goods. Journal of Choice Modelling 29:17-32

Taylor LO, Morrison MD, Boyle KJ (2010) Exchange rules and the incentive compatibility of choice experiments. Environ Resour Econ 47(2):197-220

Tol RSJ (2011) The social cost of carbon. Annu Rev Resour Econ 3(1):419-443

Torres AB, MacMillan DC, Skutsch M, Lovett JC (2015) Reprint of 'Yes-in-my-backyard': spatial differences in the valuation of forest services and local co-benefits for carbon markets in México. Ecol Econ 117:283-294

Train KE (2009) Discrete choice methods with simulation. Cambridge University Press

Uehleke R, Sturm B (2017) The influence of collective action on the demand for voluntary climate change mitigation in hypothetical and real situations. Environ Resour Econ 67(3):429-454

Yamada K, Sato M (2016) Another avenue for anatomy of income comparisons: evidence from hypothetical choice experiments. In Behavioral Economics of Preferences, Choices, and Happiness (pp. 341-384). Springer

Publisher's note Springer Nature remains neutral with regard to jurisdictional claims in published maps and institutional affiliations. 